\title{
Exploration on the Social Need Oriented Integrated Teaching Model of Human Resource Management Professional Courses
}

\author{
Shanshan Zhang*, Jiemei Yang*, Jing Xi", Yingying He ${ }^{\dagger}$ \\ School of Management, Guangdong University of Technology, Guangzhou, China

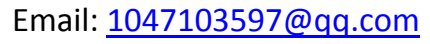

Received 28 May 2014; revised 29 June 2014; accepted 6 July 2014

Copyright (C) 2014 by authors and Scientific Research Publishing Inc. This work is licensed under the Creative Commons Attribution International License (CC BY). http://creativecommons.org/licenses/by/4.0/

\section{(c) (i) Open Access}

\begin{abstract}
In this paper, based on the survey data of typical enterprises and a key university of Guangdong province, we constructed human resource management professional's competency features based on social needs. According to the intrinsic characteristics of the human resource management theory, we put forward an "integrated teaching model", namely the integration of human resources management module of the course content as well as the integration of theoretical teaching and comprehensive quality training, so as to achieve the goal of improving teaching effects and meeting the demand of society.
\end{abstract}

Keywords

Integrated Teaching Mode, Human Resources Management, Mind Mapping

\section{Introduction}

Since the 1990s, China's colleges and universities began to attach importance to human resources management professional education, but in terms of the quantity and quality of human resource management professional talent and the current needs situation of China's economic development, human resources management professionals demand gap is huge. A large number of enterprise talent needs are not being met, because they need the

\footnotetext{
*First authors.

\#Second author.

${ }^{\dagger}$ Third author.
}

How to cite this paper: Zhang, S. S., Yang, J. M., Xi, J., \& He, Y. Y. (2014). Exploration on the Social Need Oriented Integrated Teaching Model of Human Resource Management Professional Courses. Creative Education, 5, 1181-1185. 
kind human resource management talents that have strong ability to practice. Currently a major problem of teaching mode reform faces is to improve the quality of human resources professionals. Driven by this reality problem, based on the typical enterprise in-depth interviews, we obtain a great deal of data of Guangdong province by the means of interviews and questionnaire survey of graduates majoring in human resource management, clear the human resource management professionals competency features that local enterprises need, and analyze the gap between teaching mode and the current needs of the society. Based on this, according to the intrinsic characteristics of the human resource management professional, we put forward a teaching model of "integration”, namely the integration of human resources management module of the course content as well as the integration of theoretical teaching and comprehensive quality training, to achieve the goal of improving teaching effects and meeting the demand of society.

\section{The Status of the Teaching Effectiveness of Human Resource Management}

To understand human resources management professional whole effect of classroom teaching in colleges and universities, this article selects school of management, Guangdong university of technology as the research object, conducts a questionnaire survey to its 2010 level (grade 3), 2009 level (grade 4) students majoring in human resource management, analyzes the problems of students in learning theoretical knowledge.

The university's School of Management has to about 7000 undergraduate, training of human resource management graduates each year more than 160, the scale in the top of human resource management education project in Guangdong province and even the whole country. Through the questionnaire data, we found that there are mainly two aspects of problems:

\subsection{Professional Knowledge Scattered, Lack of Systems Thinking}

Human Resource Management has six modules, including human resource planning, recruitment and configuration, training and development, performance management, compensation management, employee relations management. Although the major modules have different emphases, but each big module is precision, as well as food chain, if the lack of any link or problems will affect the imbalance of the whole human resources work system. Human resource management is an organic whole; we must adjust work focus constantly according different situations to ensure the normal operation of each link of the work. Only in this way can we maintain the benign operation of human resource management, and eventually achieve enterprise strategic objectives. Systemic of human resource management determines the students' system and comprehensive thinking model for professional courses of study. Because lacking of cohesion among human resources management professional courses and professional knowledge scattered, students are difficult to explain one module's contribution to the human resources management, the same lack of understanding of the complete human resources management operation system.

\subsection{The Disconnection between the Practice and Teaching}

Human Resource Management is a practical, applied subject. Determines by its application, we should not only teach students on solid professional knowledge, but also cultivate students' comprehensive quality and ability in the teaching, and by the means of improving the students' application ability and learning ability to improve the students' employment competitiveness and sustainable development ability in the future. Currently, the teaching objectives largely still remain the level in the students can clear and understand the contents. It did not take the initiative to help students improve the learning efficiency and learning ability, which is unfavorable to the quality of professional talents cultivation. Disconnection phenomenon comes between the practice and teaching.

\section{Human Resources Management Professional's Competency Features of Social Needs}

\subsection{Graduate Research}

For the interview subjects of graduates, we selected part of human resource management graduates (2007 level and 2008 level), who graduate from a key universities in Guangdong province, they are now engaged in human resource management in the enterprises and institutions of Guangdong province. Because they had just partici- 
pated in the work, they are the crowd the most experience the degree of match to what they have learned in school and the actual work required. From graduate's interviews, we conclude the following human resource management talent characteristics for social needs: in addition to the professional knowledge, the comprehensive quality of enterprise value are speech, communication, presentation, execution, teamwork, such as data collection and analysis ability, good ability, communication ability is the most appreciate.

In addition, they also put forward other proposals related to this. For example, in the teaching content, it is suggested that the teacher should guide students to concern the social hot spots, such as amendments to the Labor Contract Law, the minimum wage adjustment, delay retirement age, etc, and connecting with the actual interpretation of the theory of knowledge; In the teaching mode, they put forward "the upper class teachers and students", and evaluate the students, to exercise the students' speech ability and learning ability; Invite outstanding graduates back to the school to explain the required knowledge and quality in practical work combined with their own experience, and guide them how to learn professional knowledge and improve their own ability and so on.

\subsection{Enterprise Research}

Personnel training for the social needs should be subject to the local development need, and determines the direction of personnel training needs to understand the specific demand of local enterprise for human resources professionals. Therefore, the researchers visited more than a dozen enterprises' human resource workers in Guangdong Province, which covering industries including manufacturing, energy, real estate, food, investment, consulting services, and each interview conducted one to two hours. We concluded that the competency of human resources management features required for business professionals including quality and attitude, professional knowledge and skills.

1) Good comprehensive quality and positive attitude, which specifically including learning ability, communication skills, resilience, adaptability, honesty and integrity, hard-working, responsibility, initiative, self-motivated, team spirit, self-confidence, accurate self-evaluation and positioning, etc. For example, Guangzhou Pearl River Piano Group Co., Ltd., which holds that the most important ability of candidates are the comprehensive quality and attitude, they hope that candidates willing to start from the grassroots, not overly care about reward; Yuan Shun Management Consulting Co., Ltd., Guangdong, emphasizing the comprehensive quality, personality, character, responsibility, etc.; Hong Kong Xionghui Group Limited Company, which pays attention to employee's character, personality and requires good cooperation, obedience and strong ambition; South Sea Nengxing (Holdings) Limited Company, focusing on employee personality, character , which also requires active personality, good communication, careful seriously, sensitive to digital, obedience and strong sense of service; Guangzhou Seagull sanitary ware Co., Ltd., focusing on the comprehensive quality of the candidates and so on.

2) Solid professional knowledge and expertise. Solid professional knowledge and expertise is the foundation of doing the work, the Guangzhou Pearl River Piano Group Co., Ltd., which values the expertise and professional competence; Yuan Shun Management Consulting Co., Ltd., Guangdong, pay attention to the professional counterparts, etc.

In conclusion ,the result of the graduates and corporate research found that adapt to the social needs of human resources management professional talent have the following two characteristics: First, the comprehensive quality and good attitude, which manifested in learning ability, communication, resilience, honest, hard-working, responsibility, initiative, self-motivated, adaptability, teamwork, self-confidence, self-evaluation and accurate positioning, communication and presentation skills, interpersonal skills, collaboration, execution, etc.; Second, it is system of professional knowledge and skills.

\section{The Construction of Integrated Teaching Model}

Based on the survey data, we found that we must take into account the two factors of comprehensive quality and professional teaching theory in order to meet the social needs of human resources management professional, and the human resources management theory must reflect the intrinsic relationship between each major module, therefore, this paper puts forward a teaching model of "integration". The concept of "integration" can be interpreted as: two or more than two different things coordinate each other, adopt measures, methods, or in a proper way, integrate them as a whole organically, and form a measure of the synergy effect (Wang, 2010). This article 
attempts to achieve the goal of integration through the mind map courseware, autonomous + assisted classroom teaching model.

\subsection{Using the Mind Map to Integrate Various Professional Theory Modules}

In 1960s, mind maps proposed by the British scholar Tony Buzan. Mind mapping is based on scientific research on brain physiology, analogous to the natural world radiological traits, in analyzing people's handwriting habits, as well as the training of "learning disabilities" practice, gradually formed the research achievements about radioactive thinking and its graphics expression (Buzan, Zhang, \& Xu, 2005). Mind mapping is a visual characterization of specific topics constructed knowledge structure; it is also a kind of mental tools to improve cognitive construction (Shi, 2012). The construction of a mind map has the following three benefits: First, use mind maps to sort out the main courses of human resource and establish a logical relationship between the modules so that to improve teaching effectiveness, and improve students' learning ability. Second, human resources management knowledge be systematic classified and organized through the use of mind mapping, that also make the fragmentary knowledge pieces into a meaningful image and lead the students have an overall impression on the knowledge contents. Third, it makes them master correct and effective learning methods, improve their learning interest and conducive to the expansion of knowledge in the future by helping students use mind mapping.

For the "Job Analysis and Workforce Planning”, "Personnel Evaluation and Recruitment”, “Training and Development”, “Compensation Management”, "Performance Management” and other core curriculum theory teaching, we design a teaching content system that in the framework of "standard + process + method", completed the courseware mind maps, which reflect the logical relationship between curriculum. All of that can realize the standardization, systematization of the course content, easier for students to understand and grasp the knowledge. Below is a part of the mind mapping, as shown in Figure 1.

\subsection{Use "Autonomous +Assist" Teaching Model to Balance the Comprehensive Quality and Professional Theory}

Autonomous learning refers to a learning model that the students consciously, actively learn and efforts to complete the task of learning on the basis of the specific learning tasks (Chunk \& Zimmerman, 1994). Assistant learning is an activity that puts learning team as the basic form, takes advantage of the interaction between the teachings of dynamic factors to promote learning systematically, and regards group scores as evaluation standard to achieving the teaching goal (Wu \& Cheng, 2010). "Autonomous + assist” is a teaching model for the purpose of cultivating students' learning ability, information collection, analysis, induction, expression ability, evaluation ability, cooperation ability and comprehensive ability, in this teaching model, teachers and students play different roles, undertaker different responsibilities and functions. The teacher's role is the organizer and guider, rather than the porters and instructor. They shall be responsible for students' collaboration, provide the conceptual framework for the students' autonomous learning, and give training for their learning and share skills, including speech training, etc. In other word, the teacher acts as the role of scaffolding in the process of students construct knowledge system. And the role of students is autonomous learners, distributors, evaluators, no longer

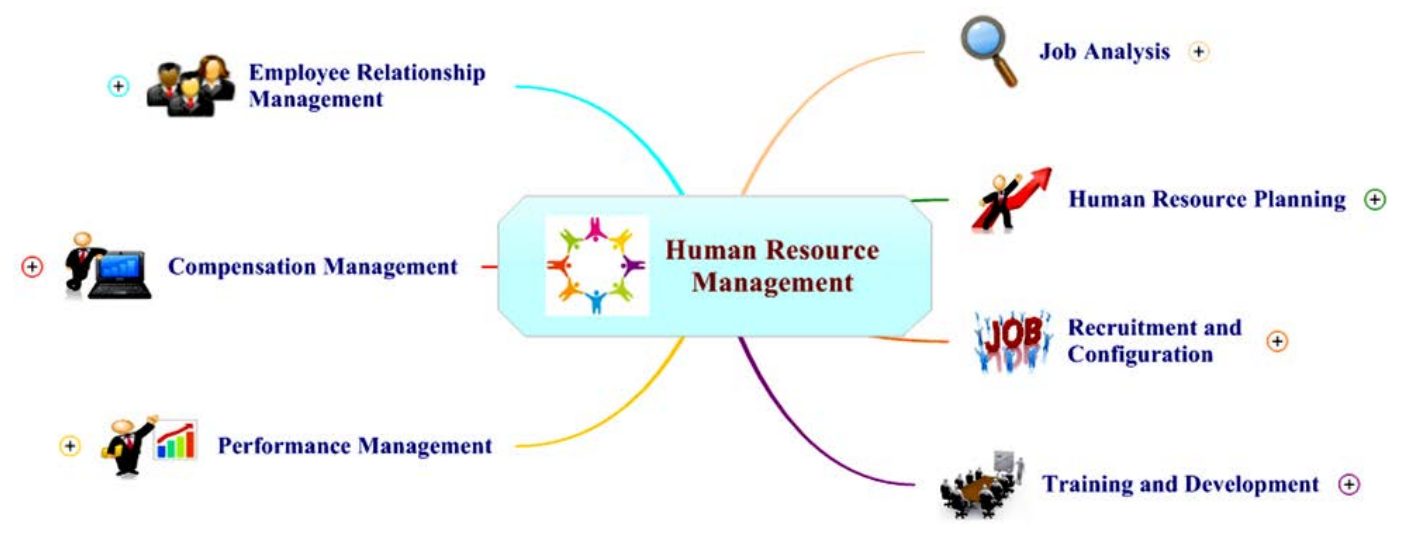

Figure 1. Mind mapping of human resources management. 
as a passive stimulus recipient. Their responsibilities are regard group as the unit, on the basis of reasonable division of labor, to choice and process external information autonomously, according to the outline that teacher before class provided, the students collect extracurricular information extensively, communicate within the group discussion, form the unit understanding of knowledge systematically, take a show and report to the class about their learning outcome, act as the temporary "teacher". And, if they do not bear the report task, they also need to make full preparation to join the discussion about the content and evaluation.

"Autonomous + assist" teaching model implementation steps are as follows: First, grouping. According to the total number of students into groups of 5 - 7 people, elected leader, subsequent activity mainly by the group as the unit; Second, pre-course counseling. Teacher gives training and guidance of thinking and expression before these activities. We have formed the relevant training courseware, such as "The Basic Principles of Thinking", "The PPT Presentation and Speech Training”, "The Business Etiquette Training”, etc. Teachers provide discussion outline in advance (including discussion topic and the case), give students a week time to prepare presentations. During this period, teacher guides students to modify the submitted PPT to ensure the quality of classroom report; Third, autonomous learning. Each groups according to the discuss outline of the data collection (textbooks, library, internet, instances), through the group's analysis and discussion, form the report, submitted to the teacher, and take a presentation; Fourth, the study results' display and communication. 3 - 4 groups take presentations of learning outcomes every class, the other groups ask questions and communicate with the topic, in this process, teacher should ensure student have a correct understanding about the knowledge; Five, teacher's reviews and supplement. Where the report group has been mentioned knowledge, the teacher will not repeat, only assess the degree of understanding of the audience. Of course, teachers need to supplement the missing knowledge or comb the necessary knowledge, give each group scoring and comments based on their performance.

\section{Conclusion}

In this paper, we grasp the enterprise of Guangdong province and the social needs for human resources management professional characteristics more accurately based on the practical research, and adopt "integration" teaching model to cultivate professional talents more effectively who meet the social needs. This teaching model has been applied in practice. The students said that the courseware, which is based on the mind map, lets them have a full grasp of the whole picture of human resource management and a deeper understanding of the intermodule relationships and the linkage between the internal systems of various modules, and these logic relationships between knowledge teaching model make learning easier and more effective. Teaching model of "autonomous + assist" gave the students a chance to collect data, to explore the professional topics, and to share results with classmates. In this process, they exercise their speaking ability, organization ability and enhance self-confidence. The more important is that it could improve their learning ability. Whether these students can quickly adapt to the needs of the society and play a professional talent after graduation is worth waiting and seeing.

\section{Funding}

This paper is financially supported by: 1) Department of Education of Guangdong project number: 1184513109; 2) University of Technology, project name: Exploration the Application Talents Oriented Integrated Teaching Mode Regarding Human Resource Management Professional Education.

\section{References}

Chunk, D. H. S., \& Zimmerman, B. J. (1994). Self-Regulation of Learning and Performance. Mahwah: Lawrence Erlbaum Associates Publishers, 56-77.

Wu, J., \& Cheng, L. Y. (2010). Autonomous Collaborative Teaching Mode under the Network Environment Research. Journal of Computer Education, 14, 4-7.

Buzan, T., Zhang, D. K., \& Xu, K. R. (2005). Brain Using Manual. Beijing: Foreign Language Teaching and Research Press. Shi, X. Y. (2012). Mind Mapping in the Role of Physics Study. Science Learning, 9, 8-9.

Wang, Z. Q. (2010). Intensive Integration Management System to Create and Practice. Beijing: China Petrochemical Press. 
Scientific Research Publishing (SCIRP) is one of the largest Open Access journal publishers. It is currently publishing more than 200 open access, online, peer-reviewed journals covering a wide range of academic disciplines. SCIRP serves the worldwide academic communities and contributes to the progress and application of science with its publication.

Other selected journals from SCIRP are listed as below. Submit your manuscript to us via either submit@scirp.org or Online Submission Portal.
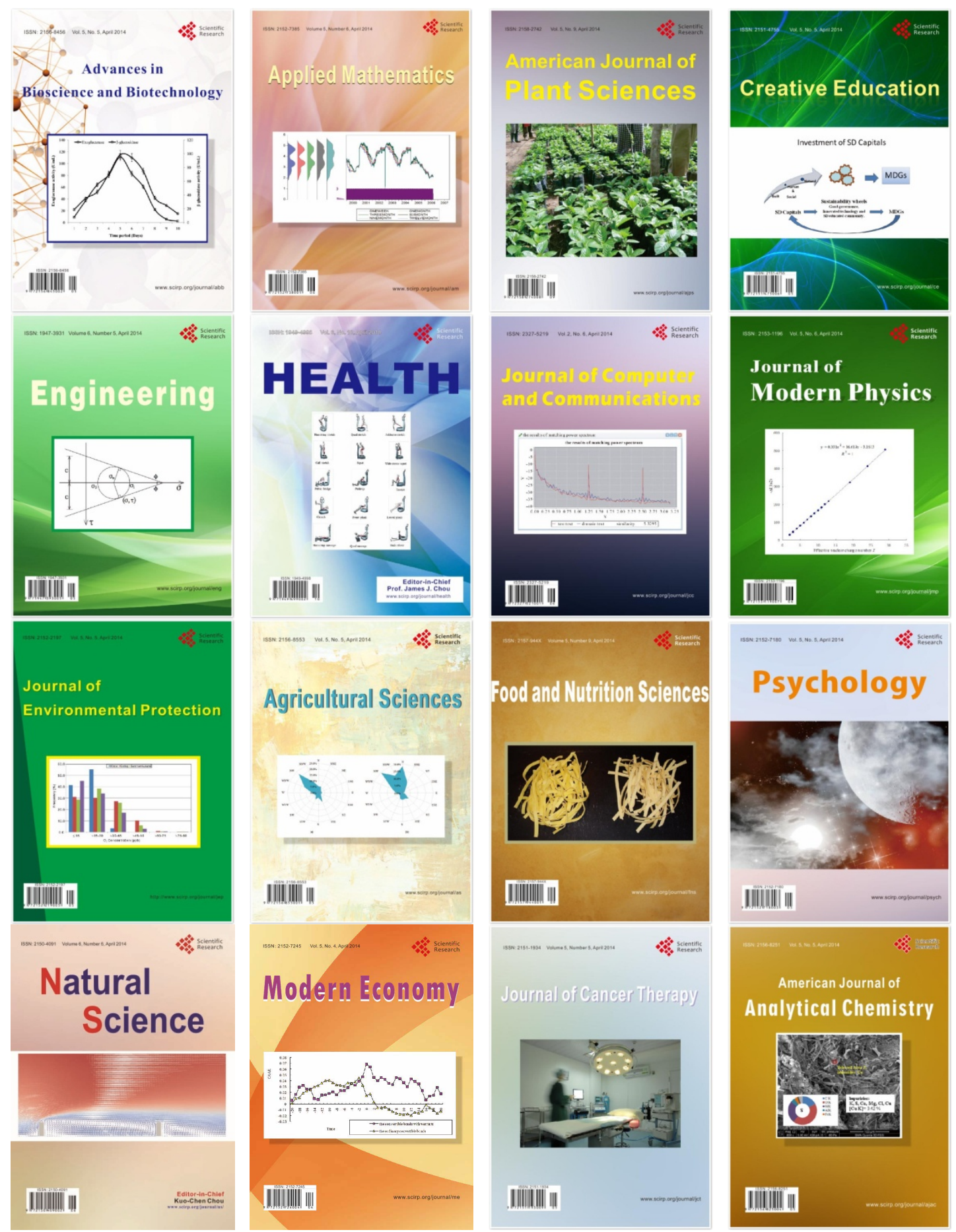